\title{
Item-level RFID for Enhancement of Customer Shopping Experience in Apparel Retail
}

\author{
S. H. Choi ${ }^{*}$, Y.X. Yang, B. Yang, and H.H. Cheung \\ Department of Industrial and Manufacturing Systems Engineering \\ The University of Hong Kong, Pokfulam Road, Hong Kong. \\ * corresponding author email: shchoi@hku.hk
}

\begin{abstract}
In the customer-oriented apparel retail industry, providing satisfactory shopping experience for customers is a vital differentiator. However, traditional stores generally cannot fully satisfy customer needs because of difficulties in locating target products, out-of-stocks, a lack of professional assistance for product selection, and long waiting for payments. Therefore, this paper proposes an item-level RFID-enabled retail store management system for relatively high-end apparel products to provide customers with more leisure, interaction for product information, and automatic apparel collocation to promote sales during shopping. In this system, RFID hardware devices are installed to capture customer shopping behaviour and preferences, which would be especially useful for business decision-making and proactive individual marketing to enhance retail business. Intelligent fuzzy screening algorithms are then developed to promote apparel collocation based on the customer preferences, the design features of products, and the sales history accumulated in the database. It is expected that the proposed system, when fully implemented, can help promote retail business by enriching customers with intelligent and personalized services, and thus enhance the overall shopping experience.
\end{abstract}

Keywords: Item-level RFID; Enhancement of Customer Shopping Experience; Apparel collocation; Fuzzy screening

\section{Introduction}

To survive and thrive in competitive apparel retail industry, companies are expected to enhance customer shopping experience (CSE). CSE refers to a total summary of a customer's interaction with a retail company beginning before the customer walks into the store and ending long after he or she leaves [1]. Therefore, a three-phase interactive experience including pre-sales, in-store, and after-sales, makes up the totality of CSE.

Before going to shop in a retail store, customers may check websites, enquire by hotlines, or search advertisements about the products of their interest. These pre-sale experiences, if satisfactory, propel customers to visit the store in person.

While shopping in the store, customers usually expect to experience proactive, informative and pleasant interactions with products and/or the store staff to fully satisfy their needs. Such in-store shopping experience hugely affects the purchase decisions of customers, and is particularly crucial to economic profit [2][3].

After sale, an interactive channel for customers to express feedbacks or seek follow-ups on the purchased products is preferably expected to establish and maintain brand loyalty and long-term relationship with the company. 
As customer decision-making for purchase has transferred from the conventionally rational view to the currently emotional and experiential view [3], apparel and fashion retailers seek to enhance CSE by providing differentiated retail experiences that can attract customers to stay longer and purchase more.

However, the traditional shopping services provided by apparel retail stores cannot fully satisfy customer needs due to a number of factors, such as difficulties in locating target products, out-ofstocks, a lack of professional assistance for selection of products, and long waiting for payments [4][5][6]. Such dissatisfactions involve various problems of decision-making, such as garment design, production scheduling, logistics management, fashion recommendation and sales prediction [7].

Artificial intelligence (AI) [8] may be used to help cope with the aforementioned problems through simulation on the decision-making behaviour of human beings [9]. During the past two decades, there have been three major AI approaches widely used in the apparel retail supply chain to enhance CSE, namely Neural Network (NN), Genetic Algorithms (GA), and Fuzzy Logic (FL).

In literature, $\mathrm{NN}$ is applied to avail apparel sales prediction [10][11]. However, according to the principle of NN technique [7], prediction models are often built on the knowledge or experience of users without sufficient theoretical support to determine the network framework and training algorithm. Therefore, extensive application of $\mathrm{NN}$ in the apparel retail supply chain tends to be impeded. GA, on the other hand, is commonly used to solve optimization problems, including production or manufacturing scheduling of apparel retail supply chain. However, it has been criticized for the shortcomings of huge computation time and slow convergence near the optimum [12].

Because of the ability to handle imprecise or vague information like human reasoning, FL has been successfully applied in apparel retail for decision support and evaluation on apparel collocation [13][14]. In [15], the literature line of FL in decision-making has been extended from single-criterion to multiple-criteria, which are more feasible and versatile in the apparel industry. Inspired by this work, we are motivated to develop a novel FL-based system to automatically generate apparel collocation recommendations for customers to enhance CSE.

However, most of the existing apparel recommendation systems are based on the knowledge and experience of fashion designers or experts [16][17][18]. Such knowledge and experience are mostly static and may easily become obsolete in the fast-changing fashion industry, resulting in unreliability of the recommendation systems. To address this issue, our proposed system applies Radio Frequency Identification (RFID) technology to capture customer shopping behaviour (CSB) data for subsequent analysis to facilitate the collocation process. The application of RFID technology in the apparel retail supply chain has gained significant interests from industries and academics over the past decades [19][20]. Moreover, item-level RFID, in which a tag is attached to each item, facilitates complete visibility of a product item from source to store to elevate inventory accuracy, on-shelf availability, store operation, and differentiated CSE [21][22] [23][24].

The non-line-of-sight communication between RFID readers and tags enables our proposed system to track in-store inventory of individual product items in real time. Moreover, the collected 
CSB data, such as which product items have individual customers browsed and/or tried on, which zones and how long customers have visited and stayed in, and what they have purchased, can be efficiently captured and stored. Through statistical analysis of the CSB, customer preferences for apparel items are obtained to generate various types of recommendations, such as apparel collocation, customer routing and sales forecast. Such recommendations can be divided into direct and indirect enhancers of in-store CSE. Direct apparel collocation recommendations provide personalized assistance in product selection for customers, while indirect recommendations help the management make appropriate marketing policies, including sales-floor layout and discount sales, to fulfil customer needs and thus provide better CSE. We present in this paper the design and implementation of direct apparel collocation recommendations.

In summary, this paper proposes an item-level RFID-enabled apparel retail management system for enhancement of in-store CSE by providing customers with leisure shopping process, interaction for merchandise information and personalized assistance in product selection. The system is primarily aimed to improve intra-organizational coordination within a retail enterprise through synchronization and management of information at item-level along the whole supply chain, with a possible extension in future development to facilitate inter-organization/crossenterprise coordination. In the front-end of the system, RFID hardware devices are installed to capture CSB for business decision-making and proactive individual marketing. In the back-end of the system, a smart apparel collocation recommendation (SACR) application is then developed to automatically generate apparel collocation recommendations, using a novel intelligent fuzzy screening (FS) algorithm based on the real-time collected CSB and apparel properties. The performance of the system is validated in an emulated apparel retail environment.

\section{Methodology for Enhancement of CSE}

\subsection{System Overview}

The proposed item-level RFID-enabled apparel retail management system based on the FS algorithm is designed to fulfil enhancement of CSE mainly from the following aspects: 1) automatic real-time generation of apparel collocation recommendations for customers in the salesfloor; 2) real-time check of product inventory to assist customers make or adjust their purchase decision; 3) efficient self-check-out at the point of sales (POS).

The workflow to achieve such enhancements is shown in Fig. 1. A customer gets an RFID tag adapted as a virtual shopping basket (VSB) at the entrance of the retail sales-floor (see Section 2.3). The communication between this tag and the RFID readers installed at apparel shelves, kiosks and POS enables various types of CSB data of the customer to be collected accordingly. Such CSB data are then stored in the CSB database of Data Management Module. In Data Processing Module, the CSB and the product properties data recorded during production are further aggregated and processed to calculate the popularity levels and fashion levels of each product category, respectively. Subsequently, these two levels are inputted to the FS algorithm for generating apparel collocation recommendations, which can be presented to customers via different networked interfaces, including RFID-enabled kiosks, personalized mobile devices, smart fitting rooms, smart mirrors and RFID-enabled POS. Such intelligent marketing assistance 
provided for customers to select desirable fashion apparel items helps enhance CSE and increase sales.

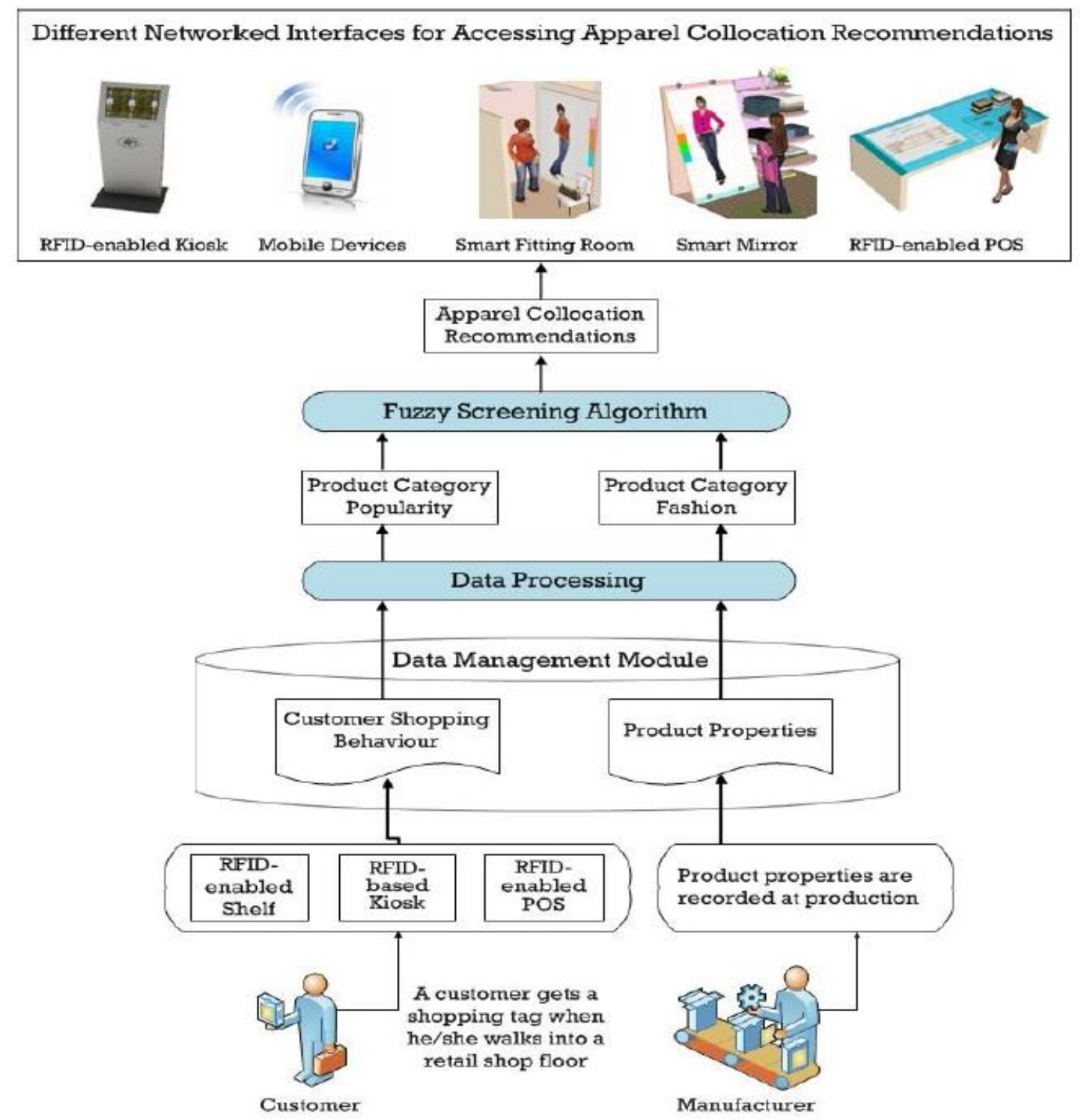

Fig.1. Workflow of the proposed item-level RFID-enabled apparel retail management system

The workflow to achieve such enhancements is shown in Fig. 1. A customer gets an RFID tag adapted as a virtual shopping basket (VSB) at the entrance of the retail sales-floor (see Section 2.3). The communication between this tag and the RFID readers installed at apparel shelves, kiosks and POS enables various types of CSB data of the customer to be collected accordingly. Such CSB data are then stored in the CSB database of Data Management Module. In Data Processing Module, the CSB and the product properties data recorded during production are further aggregated and processed to calculate the popularity levels and fashion levels of each product category, respectively. Subsequently, these two levels are inputted to the FS algorithm for generating apparel collocation recommendations, which can be presented to customers via different networked interfaces, including RFID-enabled kiosks, personalized mobile devices, smart fitting rooms, smart mirrors and RFID-enabled POS. Such intelligent marketing assistance 
provided for customers to select desirable fashion apparel items helps enhance CSE and increase sales.

This paper first presents the methodologies for collecting data of product properties and CSB are developed, followed by the application of the FS algorithm to provide apparel collocation recommendations. Accessibility to these recommendations via the RFID-enabled kiosk is implemented, while sharing through other interfaces is left for future development.

To implement the modules in the workflow, RFID hardware devices, including readers (with antennas) and item-level tags, will be installed in the apparel retail store to provide real-time inventory information, and to capture CSB data for subsequent analysis. Since the data collected from the RFID hardware devices are mostly related to huge quantities of product items, it is necessary to formulate an appropriate data format of the unique product item identifier (PID) for programming the RFID tags attached to each item during manufacturing. In the following sections, the numbering scheme for PID is introduced firstly, and the RFID hardware layout and the corresponding FS applications are then presented separately.

\subsection{Numbering Scheme for PID Format}

Based on our previous work [25], the PID adopted in the proposed system combines 96-bit electronic product code (EPC) with the unique identifier (UID) of an RFID tag. UID is a serialized number that identifies the unique chip and is hard-coded at factory level by the tag manufacturer into the transponder identifier (TID) memory (Bank 10) [26].

The numbering scheme for the EPC can be generally separated into two types, namely the openloop scheme and the close-loop scheme. The open-loop scheme is designed for the networked global marketplace, which enables universal object identifications. For instance, the EPCglobal Network provides a framework for using EPC to uniquely identify entities, store and share information through organizational boundaries [27]. In contrast, the close-loop scheme is customized for identification of product items in a specific company. It is a tailor-made numbering scheme for item-level tracking of products through an intra-enterprise supply chain.

Though the open-loop scheme provides information sharing among participants of the supply chain, it poses challenges on administration and logistics [28]. In addition, private data may be abused by some unauthorized third parties, resulting in security issues in applications of the openloop numbering scheme [29]. Therefore, the close-loop scheme is deemed more suitable for itemlevel identification of product items in the retail supply chain as it allows tailored designs for the EPC to facilitate the retailer's specific business requirements.

As such, we propose a customized close-loop EPC numbering scheme, shown in Fig. 2, to uniquely identify apparel products for our system implementation and experiments. It uses the 96-bit EPC to represent the apparel manufacturer's country code, factory code, manufacturing line number, production date, product property and a unique serial number for an apparel item. To facilitate subsequent collection of product properties for collocation recommendation applications, the 20-bit Product Property is further divided into five sub-groups to identify 
different properties of an apparel product, as in Fig. 3. This proposed EPC numbering scheme not only facilitates our research work, but may also be applied to products of similar amount of property data. For other products that require more than 20 bits to accommodate larger amounts of property data, the EPCglobal Class-1 Generation 2 (C1G2) Ultra-high Frequency (UHF) RFID tags with extended EPC memories up to 496 bits [26], such as those with Impinj's Monza 4 tag chips [30], can instead be used.

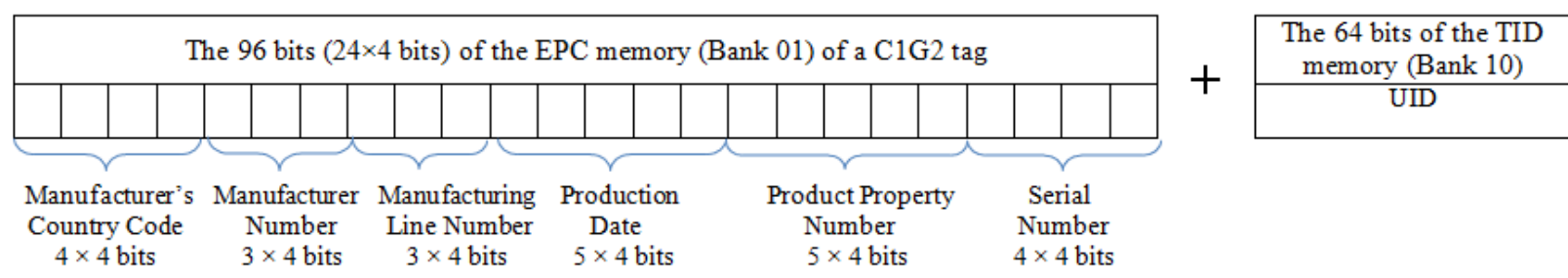

Fig.2. Customized numbering scheme for the 96-bit EPC that combines with the tag UID to form the PID of apparel products

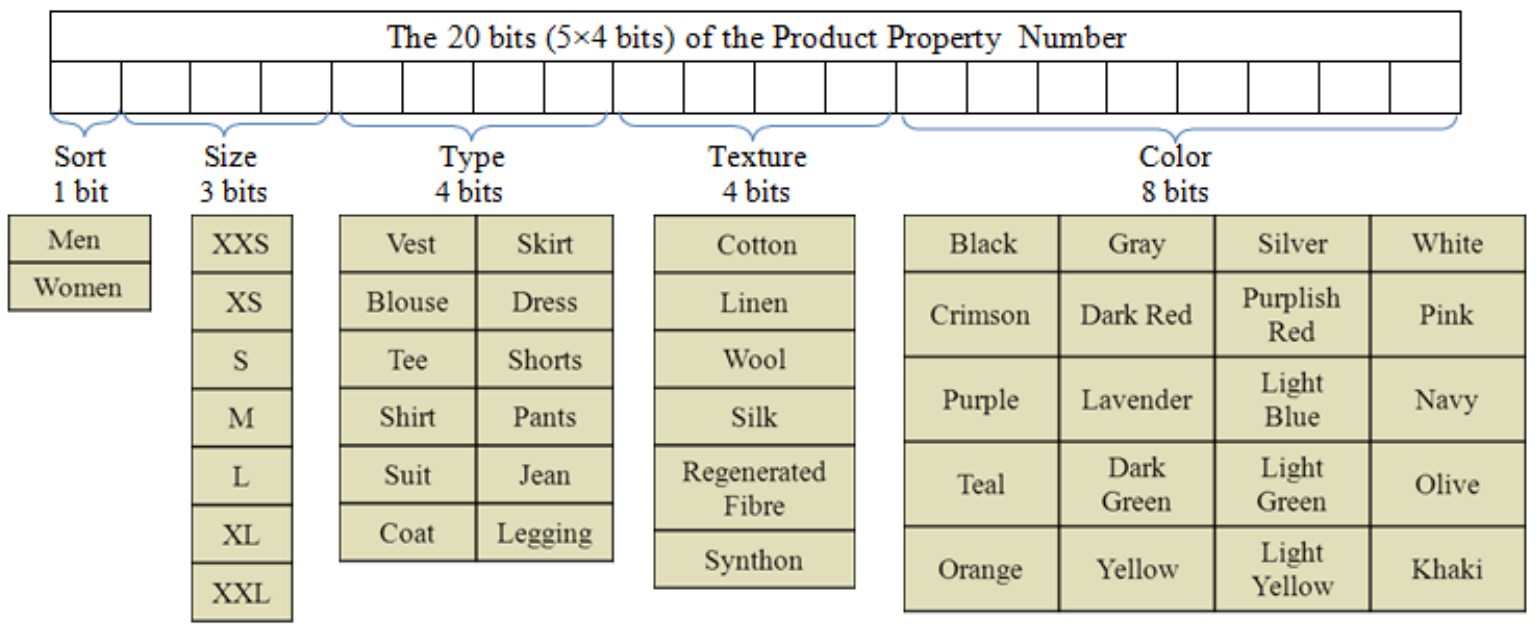

Fig.3. 20 bits for representing product property of an apparel product

\subsection{Item-level RFID for Data Collection}

With the proposed numbering scheme for RFID tags, data of the product properties and the CSB performed on apparel items can be collected accordingly to facilitate automatic generation of apparel collocation recommendations in the SACR application. To elaborate some implementation issues, we refer to the layout of an RFID-enabled apparel retail store in Fig. 4, which is equipped with RFID-enabled shelves, RFID-enabled kiosks, RFID tags, and RFIDenabled POS.

In the back-store, the PIDs of all incoming apparel items are read by the gate-door RFID readers to form the original inventory for future real-time checking. In the sales-floor, RFID reader installed in apparel shelf takes charge of the RFID tags attached to apparel products on this shelf. Certain CSB can be collected by these readers for further analysis of apparel collocation. At the self-service kiosk, which is equipped with a touch-screen tablet and an RFID reader, customers 
can conveniently check the inventory information of their selected products. Moreover, collocation recommendations for this item are displayed on the screen to enhance CSE and maximize sales opportunities. At the POS, customers can review, change or cancel their selected items. Once payment is confirmed, a sale record of that item will be updated to the back-end database for real-time synchronization of inventory.

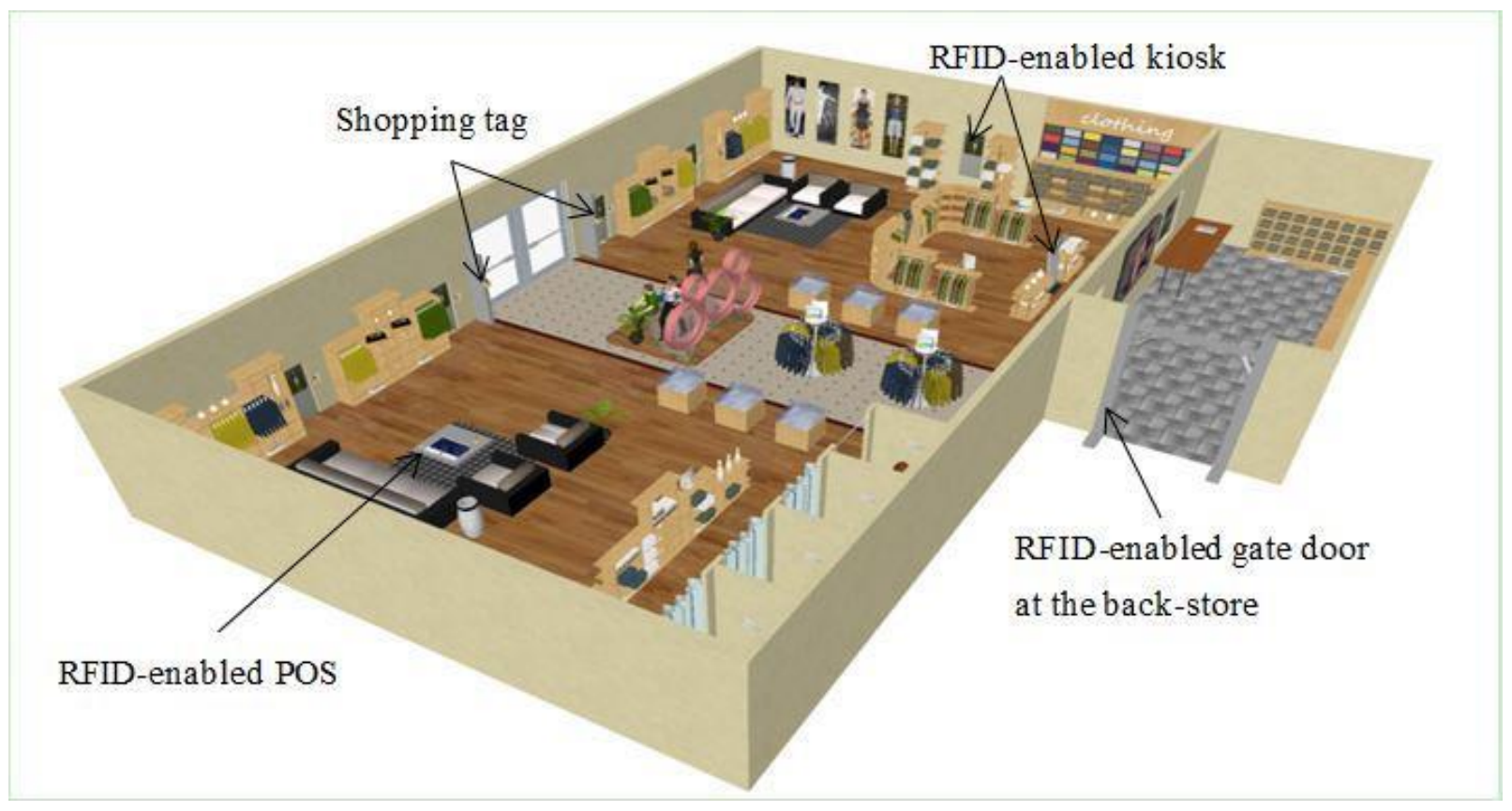

Fig.4. An RFID-enabled apparel retail store

In this system, virtual shopping baskets (VSBs) are provided for customers to record the product items they intend to buy. A VSB is a UHF RFID tag with a UID driven by a set of computer software. It is distributed to each incoming customer at the entrance or at other appropriate locations in the store, often near to the apparel shelves for easy access.

With a VSB, a customer can cart his or her selected items into a temporary table of the back-end database at RFID-enabled kiosks. The carted items are delivered to the customer after making payment by presenting the VSB at an RFID-enabled POS. At the same time, these carted items are updated as purchased items in the back-end database. The information of the associated VSB stored in the back-end database is erased, and the VSB recycled for reuse by another customer.

In this way, customers are relieved from carrying a physical shopping basket around in the store to fully enjoy their shopping. More importantly, CSB data can be collected for analysis and subsequent generation of product collocation recommendations. For customers, a VSB is simply a tiny and easy-to-carry RFID tag to replace a cumbersome shopping basket or trolley. Experimental trials indicate that users generally find it handy and efficient to use. As such, companies would be willing to introduce this technology for enhancement of CSE and improvement of business margin.

In the SACR application, the levels of product category fashion and product category popularity of apparel items are computed and analysed to automatically generate collocation recommendations for customers. 
Product category fashion is defined as how matching of a product category with other product categories. There are a number of product category properties, such as sort, size, colour and length. Only those important to apparel collocation [15] [31] are selected to calculate the fashion degree of a product category in this research. These are:

1) Sort - The sort of a product item is classified as man and woman. It determines whether the product is suitable for a male or a female customer.

2) Type - The type of a product item means it belongs to which one of design patterns of apparel items, such as tee, skirt and pants.

3) Colour - The colour of a product item.

On the other hand, product category popularity is defined as how popular of a product item is among customers during a period of time [32] [33]. It is obtained by statistically analysing the following CSB collected through the VSB.

1) The number of items browsed by customers - The RFID reader installed in apparel shelf manages a certain zone in the sales-floor. When a product in the zone is taken outside the reading range of the reader, it is counted as being browsed once.

2) The number of items carted by customers - The number of items added to the VSB by customers via kiosks.

3) The number of items sold - The number of items purchased by customers at POS.

The above CSB data are collected in an anonymous way without involving any personal data or customer privacy. Indeed, the RFID readers collect only which types of CSB have been performed on individual apparel items for further data analysis. The identities of the customers who performed the CSB are not acquired at all, and hence remain anonymous.

Since the Carted and Purchased types of CSB can be accurately recorded by collecting the times of clicking from customers on the corresponding button of the touch-screen tablet at the RFIDenabled kiosk and RFID-enabled POS separately, the collection of Browsed behaviour, which is recognized when an apparel item is detected to be taken outside the readable zone (RZ) of the shelf reader for a certain time period, may lead to the inaccurate calculation of product category popularity.

Indeed, as the investigations and researches of ergonomics and consumer behaviours [33] [34] recognized that shopping customers in the retail sales-floor tend to stand in a distance of half arm length from the product shelf for browsing as shown in Fig. 5, the RZ range of RFID reader installed on the apparel shelf can be calculated by half width of the shelf plus the half arm length as Fig. 6 shows, which also demonstrates the three zones, namely Zone A, Zone B and Zone C where an apparel item may exit according to different CSB.

1) Zone A refers to the zone where the apparel shelf is placed. RFID-tagged apparel items in this zone can be detected by the shelf reader at a high reading rate which indicates that the item hasn't been picked up by customers for browsing. In other words, there is no browsed CSB made to the apparel item if it remains in Zone A. 
2) Zone $B$ covers the zone within the RZ range of the shelf reader where the apparel item can still be detected though being picked up and taken away from the shelf. The apparel item remaining in Zone B illustrates that the shopping customer may be hesitated to bring the item for closer observation, or just caused by some naughty customers. Such behaviour is not counted as a complete browsed CSB for inference of customer preferences in the proposed system.

3) Zone $C$ identifies the zone outside the RZ range of the shelf reader where the apparel item can be hardly or even cannot be detected by the reader. As stated previously, customers tend to stand in this zone for browsing. Therefore, existence of the apparel item in this zone is counted as a complete browsed CSB to infer customer preferences in this system.

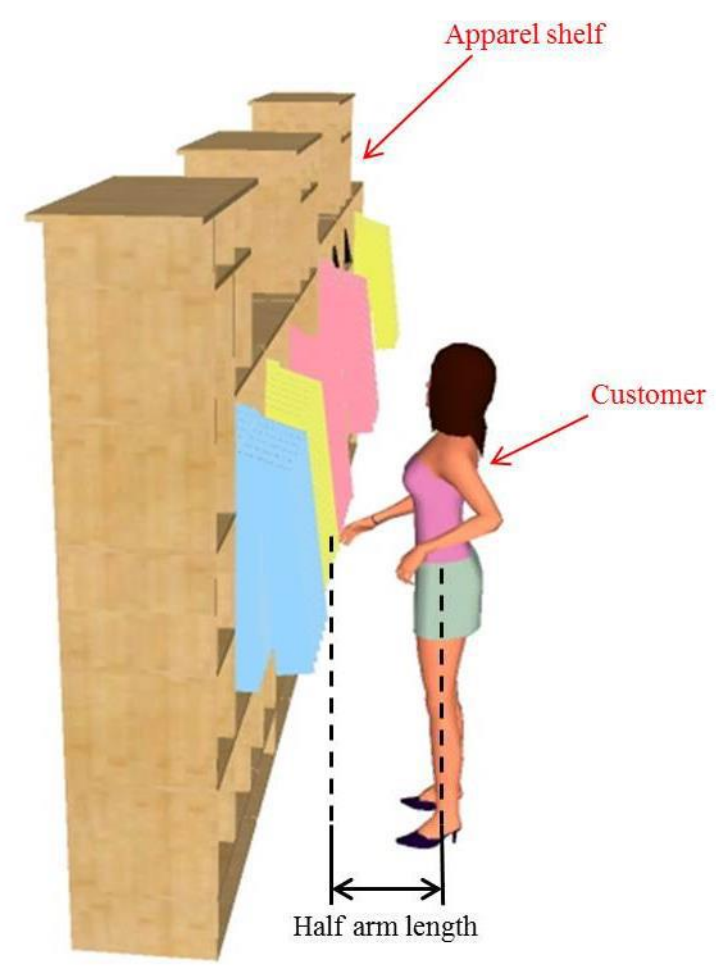

Fig.5. Browsing of a shopping customer in the apparel retail sales-floor

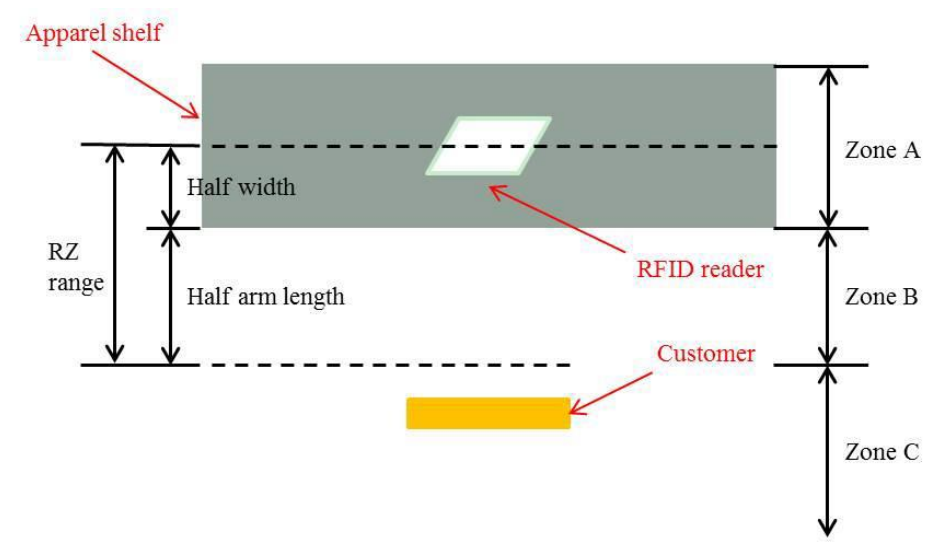

Fig.6. Division of zones for recognitions of Browsed CSB 
Therefore an innovative Browsed CSB recognition (BCR) algorithm is proposed in this paper to accurately collect Browsed CSB by recognizing the path of an apparel item among the above three zones based on the reading density of the product tag. Reading density $\rho$ is defined as total times of being read for apparel product tag (denoted as count) in a certain time cycle $T$. As shown in Fig. 7, $\rho$ is calculated for RFID tags attached to each apparel item after every tiny time interval $\Delta T$ according to Equations (1), (2) and (3).

$$
\begin{gathered}
\rho_{i}=\frac{\operatorname{Count}\left(T_{i}, T_{i+1}\right)}{T} \\
\rho_{i+1}=\frac{\operatorname{Count}\left(T_{i}+\Delta T, T_{i+1}+\Delta T\right)}{T} \\
\rho_{i+k}=\frac{\operatorname{Count}\left(T_{i}+k \Delta T, T_{i+1}+k \Delta T\right)}{T}, k=1,2, \ldots, \frac{T}{\Delta T}
\end{gathered}
$$

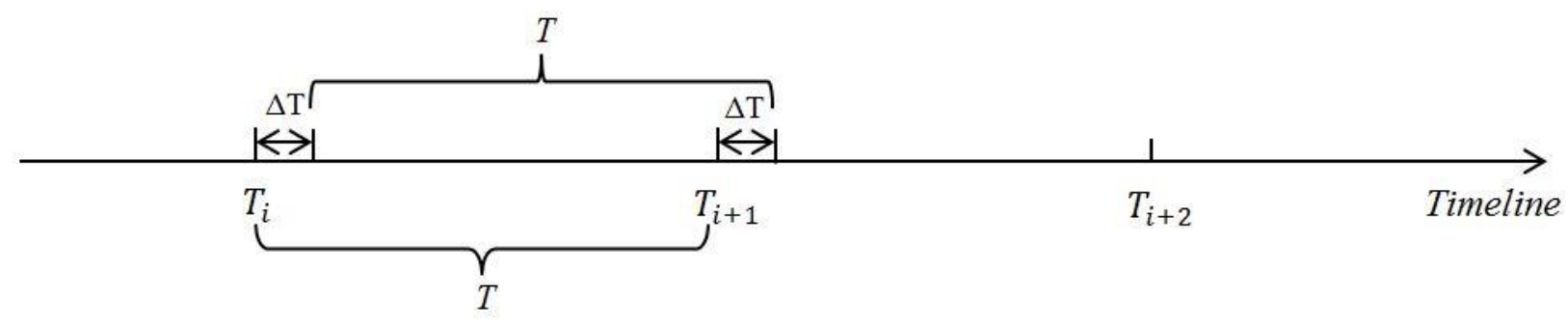

Fig.7. Calculation of reading density

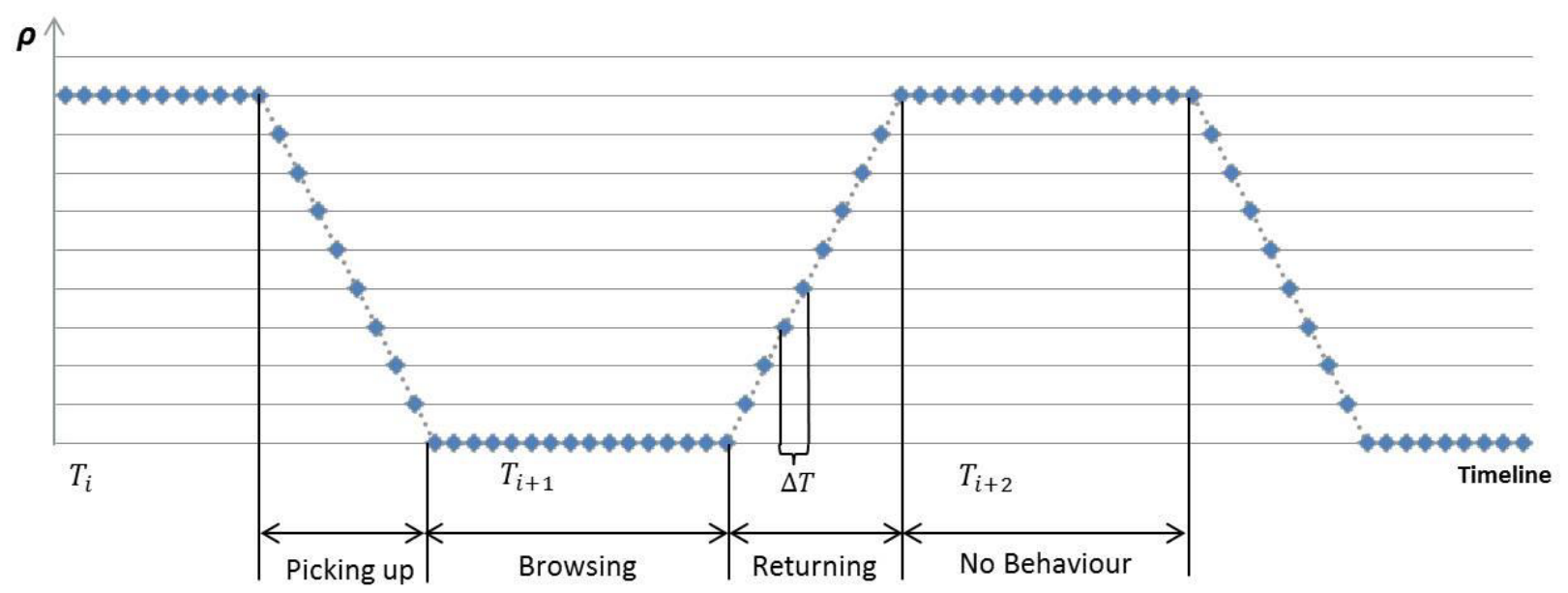

Fig.8. Ideal curve tendency of reading density for Browsed CSB

For each RFID tag, the value of $\rho$ is recorded as discrete points after every $\Delta T$ through the timeline. The value of $\Delta T$ is set in accordance with the RFID reader which equals to the time interval that the reader takes to send out RF signals for interrogation, so as to capture each change in the value of $\rho$ for accurate collection of Browsed CSB. 
Ideally, the points of $\rho$ would follow the tendency of the curve as the dashed grey line in Fig. 8 shows, which illustrates an entire process of a customer's Browsed behaviour from picking up an apparel item from the shelf, then browsing the item in a closer distance to himself or herself, and finally returning the item to the shelf.

The curve includes four phases, as follows.

1) Picking up - As the apparel item is gradually taken outside the RZ range of the shelf reader by a customer, the times it can be read go down and so does the value of $\rho$.

2) Browsing - As the apparel item has been taken completely outside the RZ for customer's closer browsing, it cannot be detected by the reader any more. So the value of $\rho$ remains zero.

3) Returning - When the customer finishes browsing and starts return the item to the shelf, the reader can detect it again and the value of $\rho$ goes up.

4) No behaviour - During this period of time, no behaviour is conducted on the apparel item by customers. As it stays in the RZ range of the reader, the value of $\rho$ remains on a relatively high level.

However, in the practical scenarios, due to the physical reading errors and various CSB types by different customers, the curve tendency that the discrete points of $\rho$ follows may subject to changes while keep the structural tendency of the ideal scenario. An example of practical curve tendency is given in Fig. 9, which illustrates fluctuations/noise may occur in the four phases of Browsed CSB. Such fluctuations/noise may subsequently result in inaccurate collection of Browsed CSB. Therefore, the BCR algorithm uses K-means clustering approach to group the discrete points of $\rho$ and process different groups accordingly, so as to filter the fluctuations/noise which is useless to infer customer preferences and collect useful Browsed CSB data for generation of product category popularity degree.

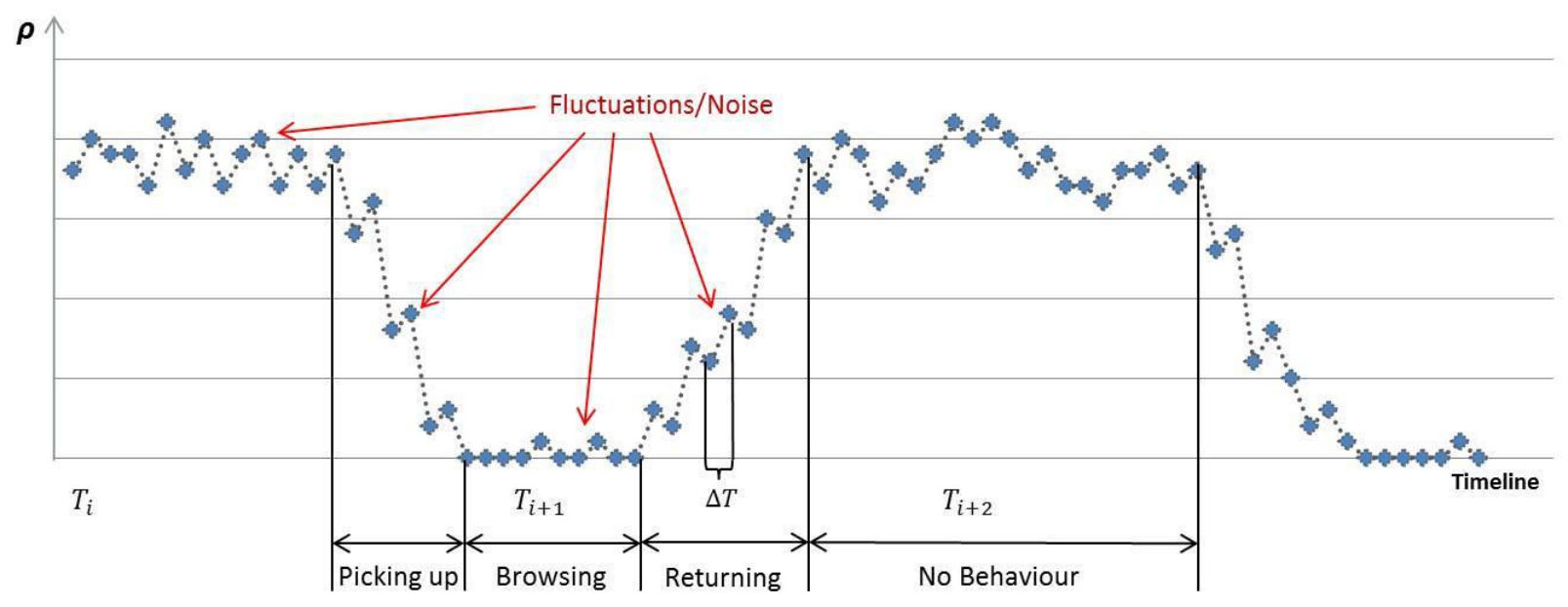

Fig.9. An example of practical curve tendency of reading density for Browsed CSB

Since the communication between RFID readers and tags may be unstable in real-life environment, the value of $\rho$ may differ at the reader level and tag level. $\rho_{r}$ denotes the 
interrogation density at the reader level which equals to how many times the reader send out RF signals to detect tags per second. $\rho_{t}$ denotes the response density at the tag level which refers to how many times the tag receives the interrogating RF signals sent by the reader per second. As $\rho_{r}$ and the reading rate $(\gamma)$ is determined by the settings of RFID hardware, $\rho_{t}$ can be obtained as follows.

$$
\rho_{t}=\rho_{r} \times \gamma
$$

Therefore, the initial cluster centre is set at $0, \rho_{t} / 2$ and $\rho_{t}$ to cluster the data set of response density $P=\left\{\rho_{i}\right\}(i=1,2, \ldots, n)$ into three zones, namely High Zone (HZ), Medium Zone (MZ) and Low Zone (LZ) as shown in Fig. 10, which is corresponded to Zone A, Zone B and Zone C as stated previously.

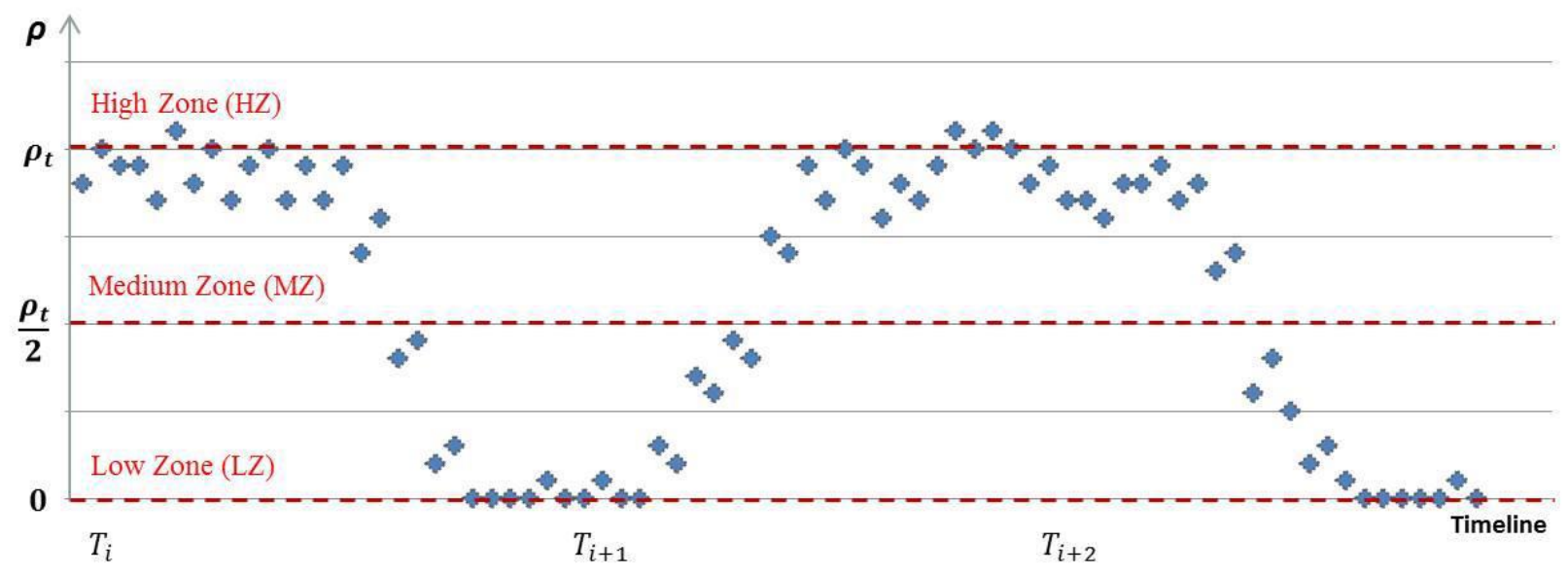

Fig.10. K-means clustering for reading density

1) High Zone $(\mathrm{HZ})$ has the cluster centre of $\rho_{t}$ which indicates the existence of the RFID-tagged apparel items in Zone A. The tags in this zone can be more possibly detected by the shelf reader, thus resulting in relatively higher value of response density $\rho_{i}$.

2) Medium Zone (MZ) has the cluster centre of $\rho_{t} / 2$ which represents that the RFID-tagged apparel item exits in Zone B. The shelf reader can still detect tags in this zone, yet at a lower reading rate comparing with that at Zone $\mathrm{A}$.

3) Low Zone ( $L Z)$ is the cluster with centre at 0 which categorizes the RFID-tagged apparel item existing in Zone $\mathrm{C}$. It is hard for the shelf reader to detect tags in this zone. Hence, the value of $\rho_{i}$ remains at a relatively lower level or even 0 level indicating no communication between the RFID reader and tag.

The Euclidean distances between each $\rho_{i}$ and the three cluster centres are calculated as follows.

$$
d_{i}=\left\{\left|\rho_{i}-\rho_{t}\right|,\left|\rho_{i}-\rho_{t} / 2\right|,\left|\rho_{i}-0\right|\right\}
$$

With that, each value of $\rho_{i}$ will be assigned to the nearest cluster, whose centre provides the smallest Euclidean distance to $\rho_{i}$. For instance, if the minimum value of $d_{i}$ equals to $\left|\rho_{i}-\rho_{t}\right|$, then $\rho_{i}$ belongs to the HZ. 
Fig. 11 illustrates the flow chart of the BCR algorithm. Loop I, Loop II and Loop III separately process $\rho_{i}$ in HZ, MZ and LZ, such that only under the circumstance that an apparel item has been taken away from Zone A to Zone C, one and only one time of Browsed CSB will be recorded in the database. As a result, accurate Browsed CSB is collected to infer customer preferences for generation of apparel collocation recommendations.

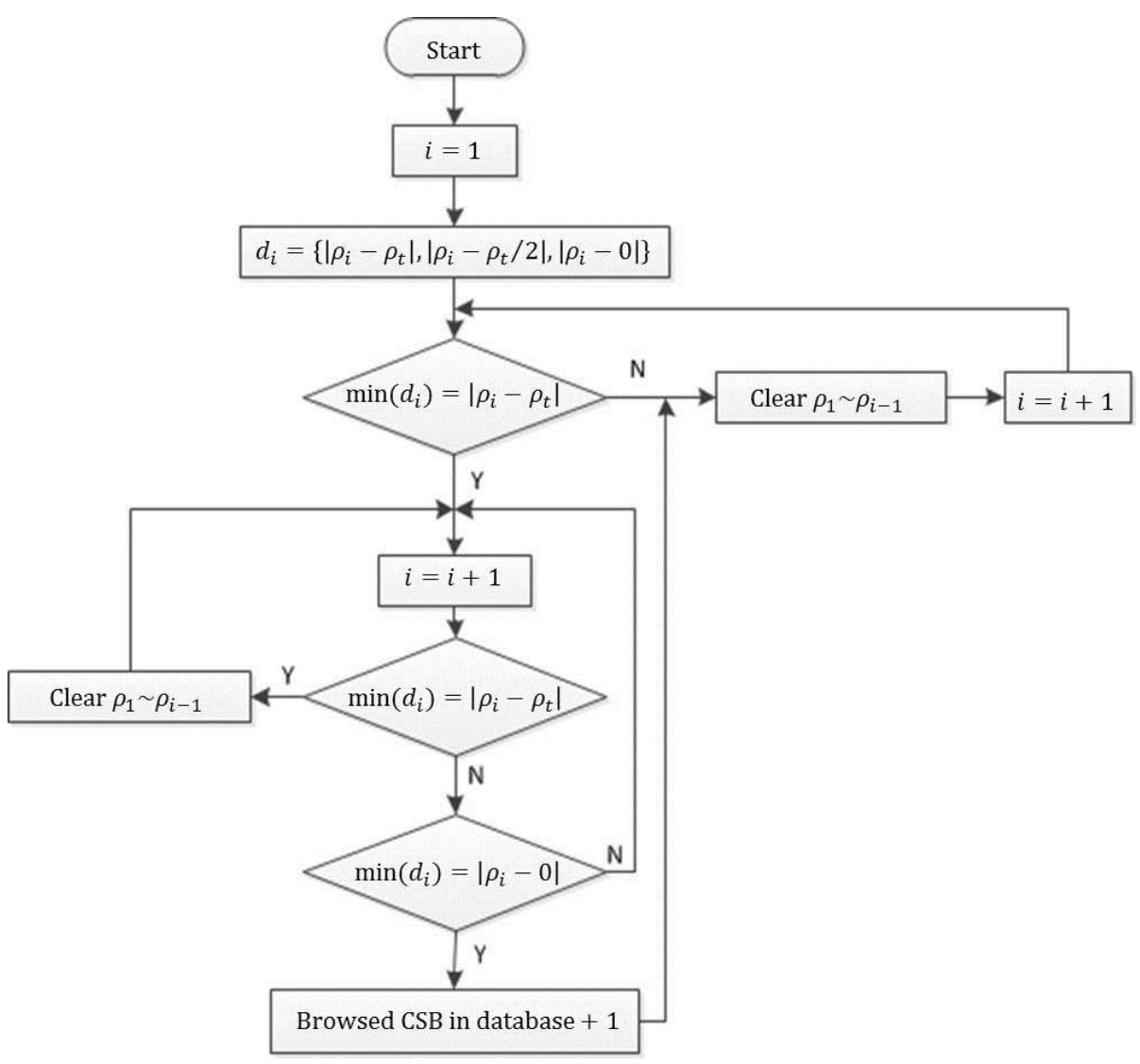

Fig.11. Flow chart of BCR algorithm

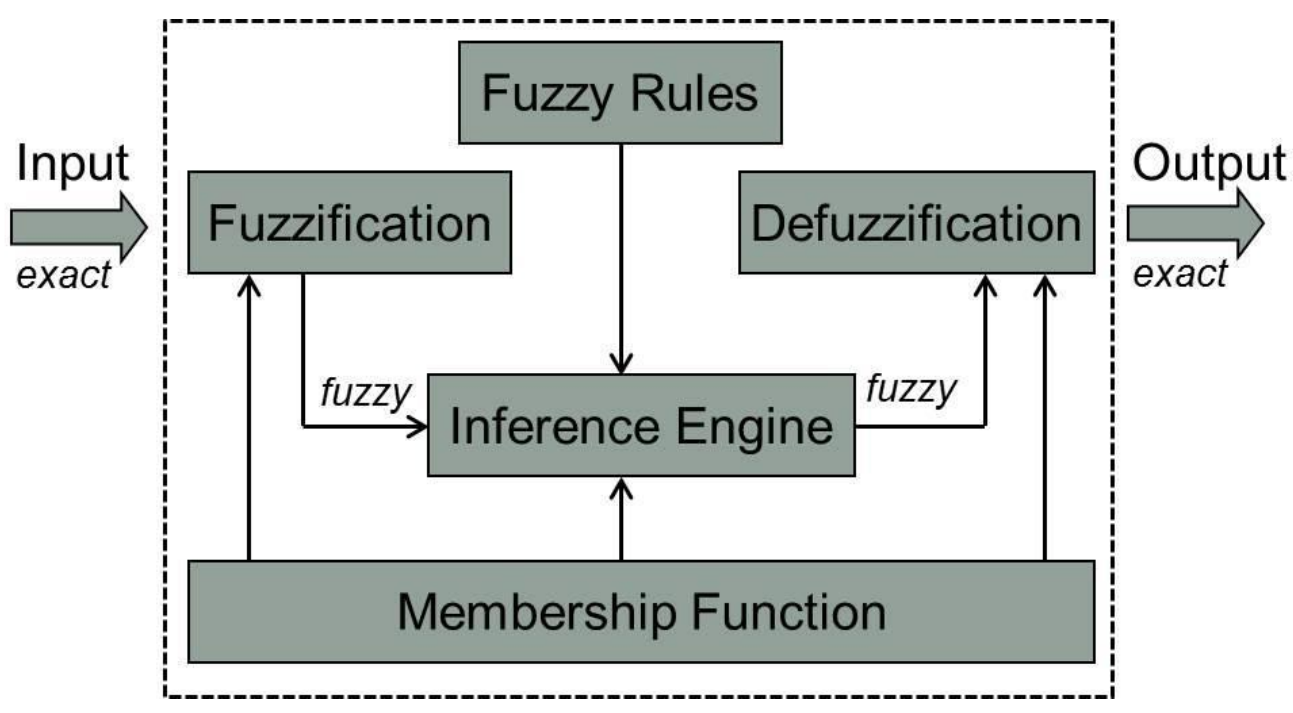

Fig.12. Flow of fuzzy screening 


\subsection{Fuzzy Screening for Apparel Collocation}

An FS algorithm usually involves five components, as shown in Fig. 12. Fuzzification transforms the exact input values into fuzzy values. Then fuzzy models are built for these values based on prior rules by the inference engine. Finally, those fuzzy results given by inference engine are transformed back into exact output by defuzzification. Membership functions define the transforming rules for fuzzification and defuzzification [35].

\subsubsection{Overview of the SACR application}

Based on the FS algorithm, the SACR application is developed to automatically generate apparel collocation recommendations whose flow is shown in Fig. 13. Every two apparel items stored in the back-end database can generally be matched with each other, possibly resulting in a huge amount of collocations without any professional or practical basis. Then based on the widespread fashion design expertise, one apparel item is collocated with another according to their design features.

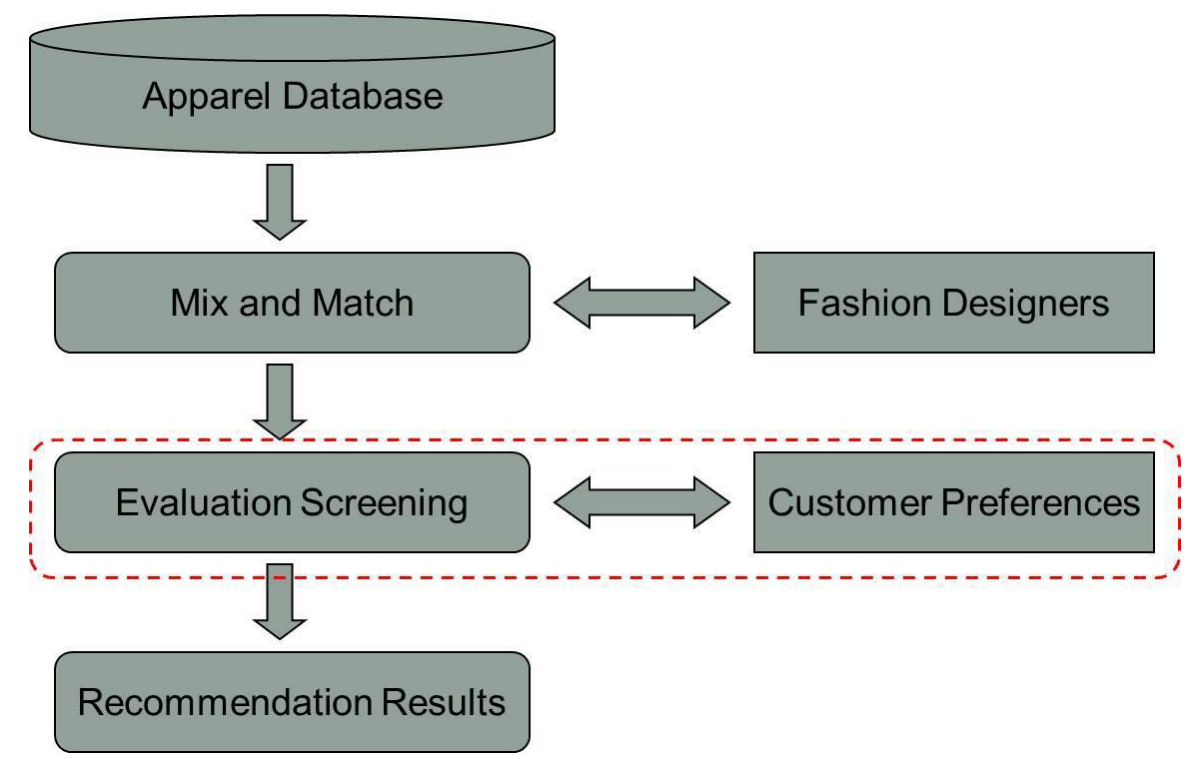

Fig.13. Flow of SACR application

In other words, how well these two items go with each other on the design characteristics, including sort, type and colour, is checked and valued to select a relatively small subset from the previous large class of alternatives. Subsequently, customer preferences are introduced into the apparel collocation process.

The degree of product category popularity is transformed from the accumulated CSB, and then used to conduct the evaluation screening on the subset of collocation alternatives selected by fashion design expertise. Since the preferences of customers may be changing, this evaluation factor facilitates the entire recommendation approach to be dynamic and able to adjust to the volatile marketplace, thus enhances the satisfaction of end-consumers in the supply chain.

\subsubsection{Presentation of rules for apparel mix and match}


From the perspective of apparel design, different apparel items can be described by a variety of properties, such as sort, type, and colour. These properties can be used to identify the properties of matching results, such as gender, occasion and age. By collecting fashion design expertise [15] [31], the system proposes from the matchup relationship in Fig. 14. That is, when the properties of two apparel products for collocation are inputted, the properties of this matching result can be generated accordingly.

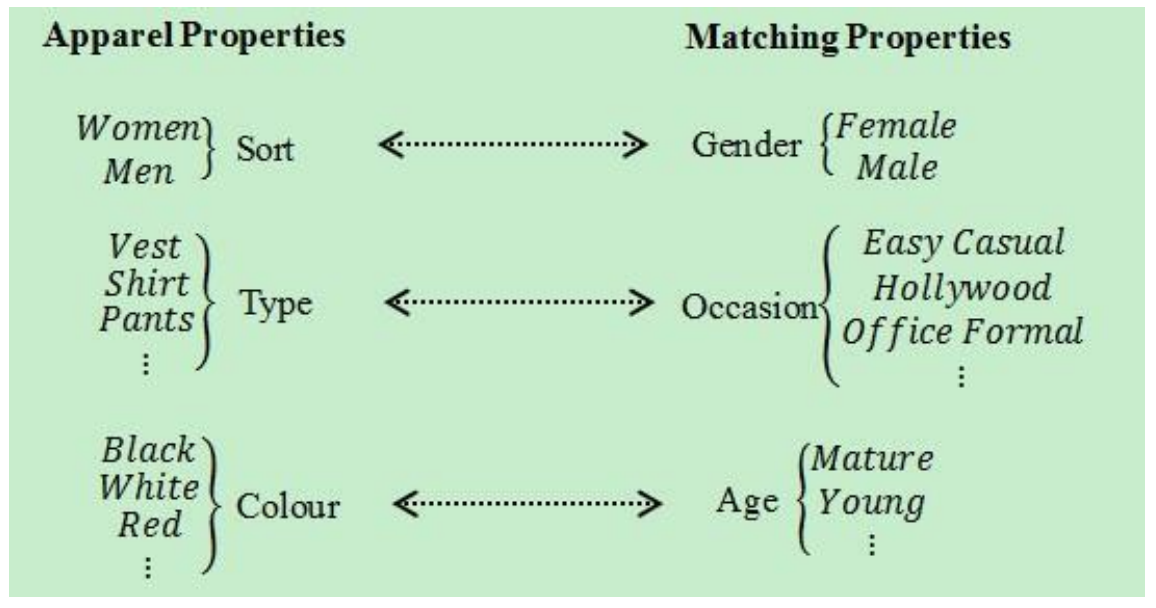

Fig.14. Relationship between apparel properties and matching properties

As the properties are described in linguistic terms, a rule-based algorithm is used to generate Ifthen rules to formalize them into a model that can be understood and ratiocinated by a computer, in order to take advantage of the high effectiveness of If-then rules in dealing with linguistic and categorical data. The rules to identify apparel matching properties in accordance with their individual properties can be expressed as the "IF-THEN" rules as follows.

1) IF property value of $A_{i}$ of one apparel item is $q(m)$ AND property value of $A_{i}$ of another apparel item is $q(n)$,

2) THEN the matching property value of $C_{j}$ of this collocation result is $s(k)$,

where $A_{i}$ is the $i t h$ property of apparel item that corresponds to the $j$ th matching property which is represented by $C_{j}, q(m), q(n)$ are the enumerated value of $A_{i}$ and $s(k)$ is the enumerated value of $C_{j}$ which are all presented in the linguistic form. For instance, IF the colour of one apparel item is red and the colour of another item is white, THEN the age for this collocation result is young.

\subsubsection{Determination of linguistic grading}

From a human perspective, the evaluation of whether an apparel collocation result is good or bad is represented by the collocation degree in linguistic terms such as high, medium and low. However, such literal and vague information complicates computer processing. Thus, a set of fuzzy numbers are employed to represent the linguistic grading terms of product category popularity and product category fashion for the final apparel collocation recommendations in this research. The linguistic terms describing these two degrees are appropriately transferred into a corresponding fuzzy number by Gaussian function, as shown in Table 1. 
Table 1 Determination of Linguistic Grading

\begin{tabular}{|c|c|c|}
\hline $\begin{array}{c}\text { Linguistic } \\
\text { terms of } \\
\text { degrees } \\
\text { function }\end{array}$ & $\begin{array}{c}\text { Membership } \\
e^{\frac{(x-\mu)^{2}}{2 \sigma^{2}}}\end{array}$ & $\begin{array}{c}\text { Approximated value } \\
\text { of corresponding } \\
\text { fuzzy number }\end{array}$ \\
\hline $\begin{array}{c}\text { Very } \\
\text { High(VH) }\end{array}$ & $\mathrm{G}(9,0.8)$ & 9 \\
\hline High(H) & $\mathrm{G}(7,0.8)$ & 7 \\
\hline Medium(M) & $\mathrm{G}(5,0.8)$ & 5 \\
\hline Low(L) & $\mathrm{G}(3,0.8)$ & \\
\hline $\begin{array}{c}\text { Very } \\
\text { Low(VL) }\end{array}$ & $\mathrm{G}(1,0.8)$ & \\
\hline
\end{tabular}

Since the numbers of times of different CSB made to apparel items have been collected by RFID hardware devices as stated previously, rules of monthly market prediction [36] and arithmetic grading [37] are adopted to transform the times into popularity degree to facilitate the subsequent collocation algorithms. As Fig. 15 demonstrates, in every business day, the back-end database would store how many times each apparel item has been browsed, carted or purchased. When collocation is required for an apparel item, the system would examine the recorded times of this item over the previous 30 days to search out the maximum one, and then divide the maximum value into five ranges arithmetically to represent the descriptive linguistic term, as shown in Fig. 16 , and ultimately presented by fuzzy numbers.

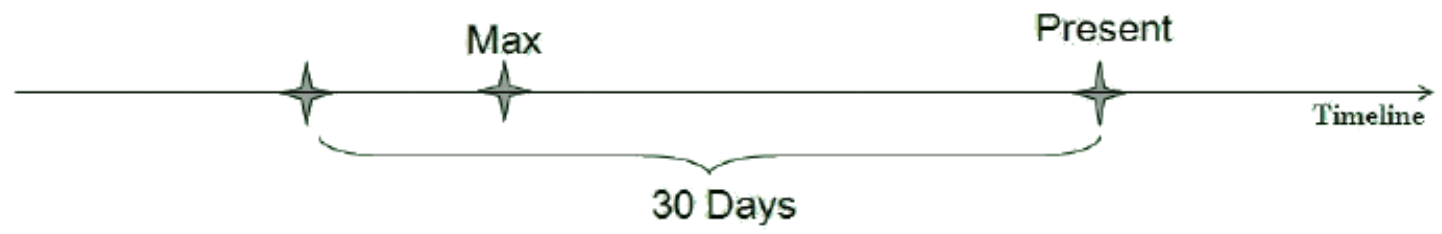

Fig.15. Monthly market prediction

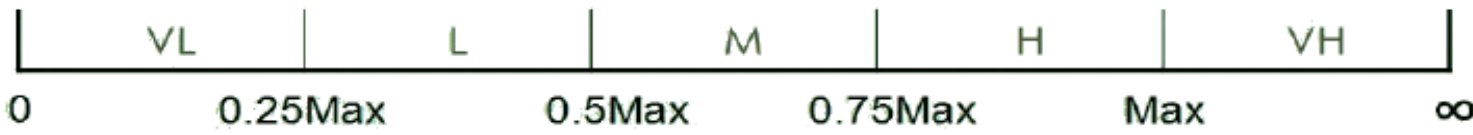

Fig.16. Arithmetic grading

\subsubsection{Evaluation screening using the FS algorithm}

The FS algorithm using S- and R- implication operators is adopted in the system since the operators have been proved to have better performance in selecting a small subset from a large 
class of alternatives than other general implication operators [38] [39]. Fig. 17 illustrates the fuzzy screening process according to the $\mathrm{S}$ - and $\mathrm{R}$ - implications given by:

$$
\mathrm{x} \rightarrow \mathrm{y}=\min \{1-\mathrm{x}+\mathrm{y}, 1\}
$$

where $\mathrm{x}$ and $\mathrm{y}$ represent the degrees of product category fashion and product category popularity respectively, while the maximum value 1 applies to the highest value of the fuzzy numbers, which refers to the largest Gaussian fuzzy number of 9 representing the highest linguistic grading term in this research.

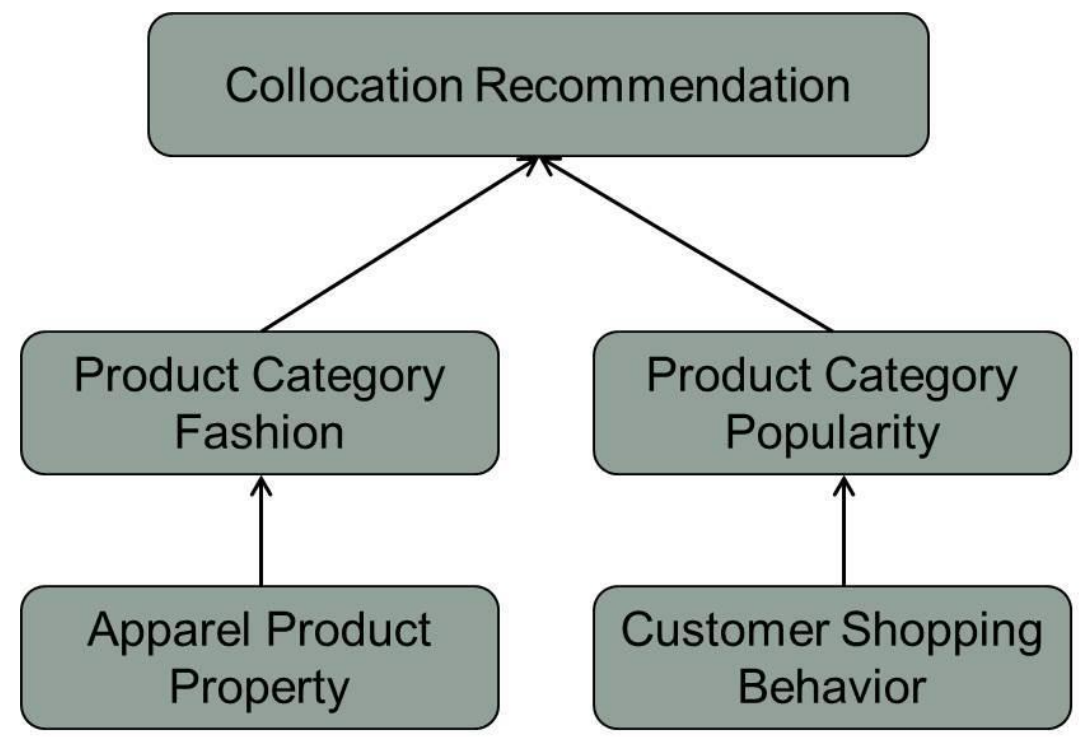

Fig.17. Operation process of SACR application

The SACR application operates as the following four steps to generate recommendation degrees of each collocation pairs using the FS algorithm with S- and R-implication operators.

Step 1: Acquisition of input factors

The input factors for the proposed FS algorithm using S- and R- implication operators, including:

1) The apparel product properties of each individual apparel item for mix-and-match operation;

2) The numbers of times of different CSB made on every single apparel item for evaluation screening;

3) The inference rules to generate matching properties from the apparel product properties.

The first two factors can be acquired by RFID hardware devices installed at different locations of the apparel retail store as described in the previous sections, while the IFTHEN rules for collocation inference are predefined and complied in the computer software applications with respect to fashion design expertise.

Step 2: Generation of product category fashion degree 
Each of the apparel items stored in the back-end database can be matched with another to form a collocation pair. Based on the inference rules introduced previously, the degree of product category fashion is transformed into Gaussian fuzzy numbers from the exact input value of apparel product properties, considering how well those two product items match with each other on their design features, such as sort, type, and colour.

Step 3: Generation of product category popularity degree

The numbers of times of different CSB made on individual apparel items are captured by RFID hardware devices and accumulated in the back-end database. Such numbers of times are transformed to the degree of product category popularity presented in Gaussian fuzzy numbers using approaches in Fig. 15 and Fig. 16.

Step 4: Generation of apparel collocation recommendation degree

With the degree of product category fashion $(F)$ and product category popularity $(P)$ obtained, the final degree of recommendation $(R)$ for each collocation pair is calculated by the FS algorithm using S- and R- implication operators, as follows.

$$
P \rightarrow F=R, \quad R=\left\{\begin{array}{cc}
9, & P \leq F \\
9-P+F, & P>F
\end{array}\right.
$$

This approach employs the $P$ degree to screen out a small subset of optimal $F$ degree to provide the final $R$ degree, which balances fashion expertise with customer preference.

Therefore, the SACR application can recommend optimal apparel collocation pairs to help enhance CSE on the basis of the ranked value of $R$, where a higher value indicates a stronger recommendation, because such collocation pairs go well with fashion expertise and customer popularity according to the CSB collected in real time. This ensures both fashion expertise and customer preference are integrated for consideration. Indeed, even if some collocations receive more visits by customers and thus rank higher in the $F$ degree, they may not be recommended if the $P$ degree is low, and vice versa.

Comparing with the existing systems for apparel collocation, the proposed FS algorithm generates apparel collocation recommendations based not only on the static design features of apparel product items, but also on the dynamic customer preference on the product item, which is inferred from the real-time CSB data collected by RFID hardware devices. Such recommendations are more adaptive in the versatile apparel industry to satisfy customer requirements.

\section{System Implementation and Validation}

The proposed item-level RFID customer shopping experience enhancement (IRCSEE) system was established in Microsoft Visual Studio 2010. Microsoft Visual C\# was used to develop the various functions and operation interfaces of the system. In addition, Microsoft SQL Server 2008 was used for the system to store and manage the back-end database. In order to validate the feasibility and robustness of the IRCSEE system, an emulated RFID-enabled apparel retail environment was established in the laboratory. Such environment was used as the scene of system application to validate the performance of the system modules in providing satisfied apparel collocation recommendations based on the real-time CSB data collected by RFID hardware 
devices. The following sections describe the details about the data preparation, emulated apparel retail environment establishment, experimental operation and result analysis of the validation experiments.

\subsection{Data Preparation}

According to the mechanism of the proposed FS algorithm, the data of product properties, collocation rules, popularity degrees and samples for validation were prepared. The list below shows the acquired data of 100 individual items which belong to two sorts including men and women, 12 product types, such as blouse, shirt and pants, and 20 different colours including black, white, pink and so on.

1) The properties of each apparel item, including sort, type and colour;

2) Collocation rules with reference to the fashion expertise and literatures to generate collocation pair properties from individual item properties;

3) Degrees of product category popularity for each collocation pair which are calculated dynamically based on the real-time CSB collected by RFID devices in the emulated apparel retail environment. To save the experimental time, the accumulated historical times of Browsed, Carted and Purchased CSB made on each apparel item are previously assigned by a random number function and stored in the back-end database. Then when new CSB data are collected in the validation experiments, such accumulated data, and hence the degree of product category popularity, would change accordingly;

4) A total of 50 sample pairs collocated among the 100 items under the recommendation of fashion expertise, which are used to compare with the pairs recommended by the proposed FS algorithm for validation of its performance.

As such, the static degree of product category fashion considering fashion expertise and the dynamic degree of product category popularity indicating customer preferences are prepared in the back-end database for generation of apparel collocation recommendations.

\subsection{Establishment of Emulated Apparel Retail Environment}

The RFID-enabled apparel retail store described in Section 2 comprises a number of shopping cells. A shopping cell, which is consisted of an RFID-enabled apparel shelf and the application of RFID-enabled kiosk and RFID-enabled POS, is established in this experiment for validation of the IRCSEE system as shown in Fig. 18. RFID-tagged apparel items are placed on the shelf equipped with an RFID reader. Another RFID reader for kiosk and POS application to interrogate the VSB tag held by customers are placed near the computer screen for user interface. These two RFID readers are controlled by the back-end computer system via connection to the wireless router to facilitate operation of the IRCSEE system. Fig. 19 illustrates the user interface of the IRCSEE system for interaction with customers in a shopping cell. 


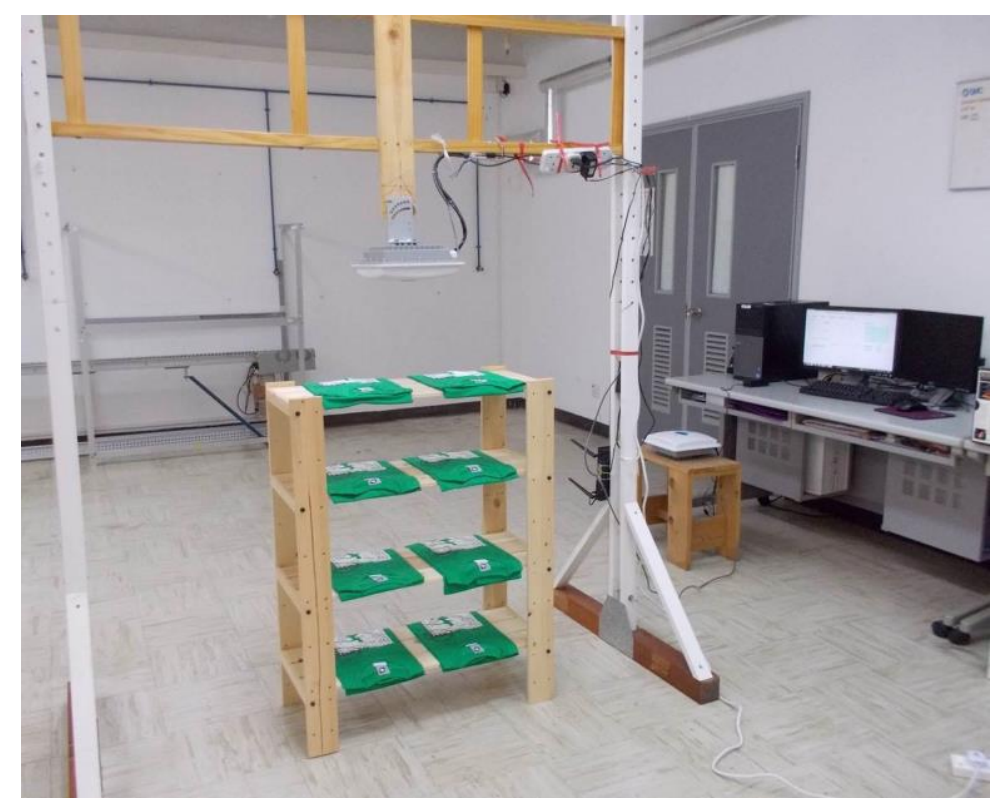

Fig.18. A shopping cell in the RFID-enabled apparel retail store for validation of the IRCSEE system

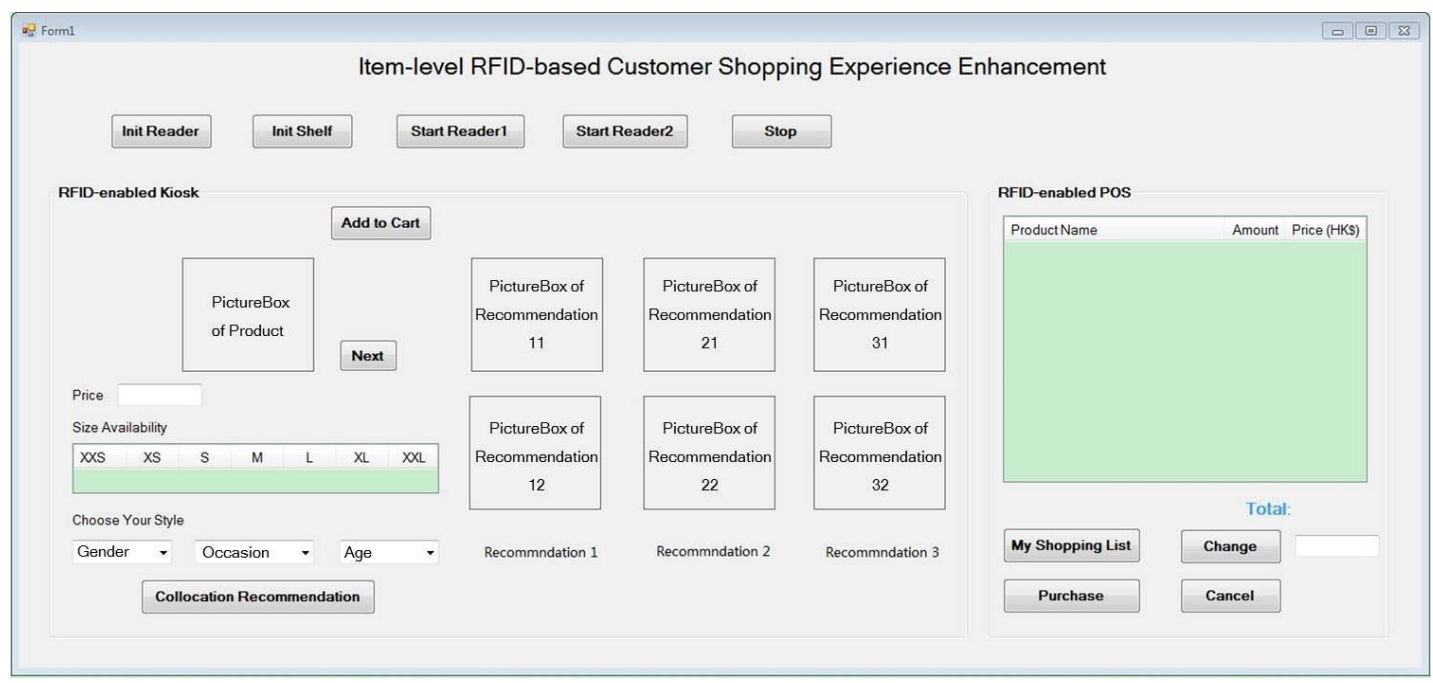

Fig.19. User interface for validation of the IRCSEE system

\subsection{Experimental Operation and Results Analysis}

Since the performance of the IRCSEE system is greatly influenced by the reading accuracy of the RFID reader determined by the hardware settings, this validation experiments tested the capability of the IRCSEE system in providing satisfactory collocation recommendations for customers at different reading rates of the RFID hardware devices.

At each reading rate, 10 parallel trials are conducted in the shopping cell. In each trial, five customers are recruited to emulate the shopping process in half an hour. They can browse apparel items on the shelf, go to the kiosk to cart their preferred items and obtain collocation recommendations, or check-out at the POS. The performance of the IRCSEE system is measured by percentage of recommendation accuracy (RecomAcc). 


$$
\text { RecomAcc }=\frac{\text { Recommendation }_{\text {same }}}{\text { Recommendation }_{\text {total }}} \times 100 \%
$$

where Recommendation $_{\text {same }}$ is the number of collocation pairs recommended by the IRCSEE system which are included in the 50 sample pairs and Recommendation total $_{\text {is }}$ is the tal number of collocation pairs recommended by the system.

Fig. 20 shows the experimental scene at $100 \%$ reading rate where four customers are browsing apparel items around the shelf and one customer is checking product information via the user interface of the kiosk.

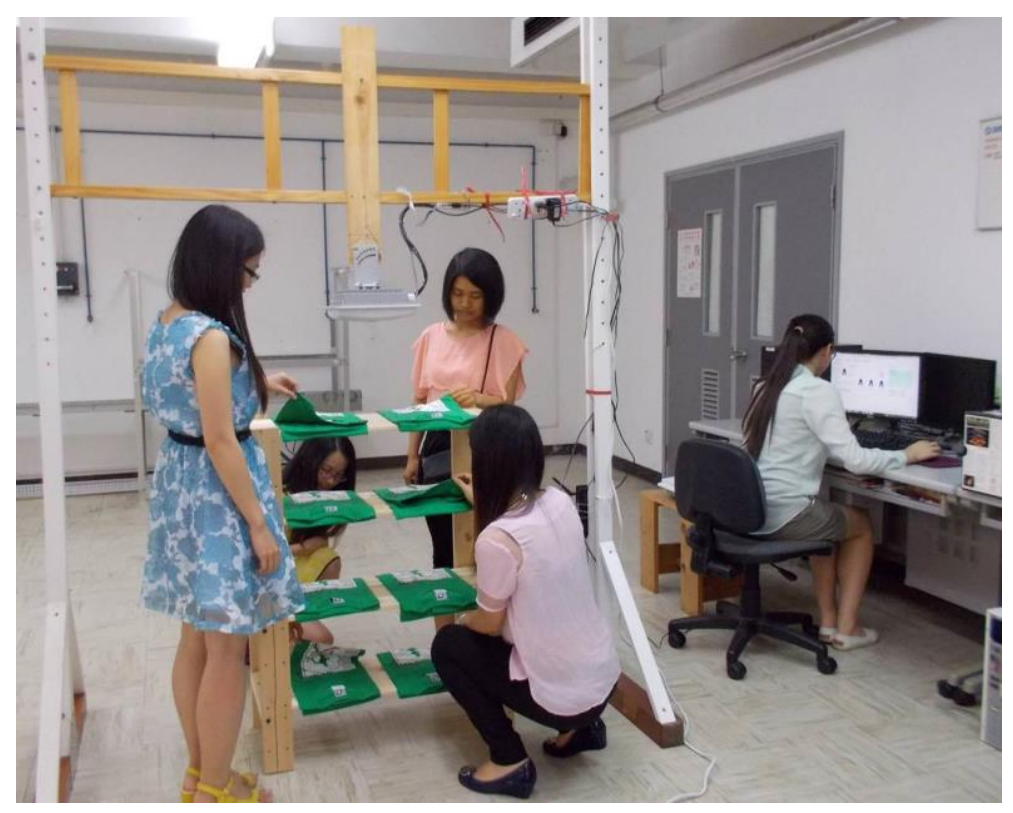

Fig.20. Experimental scene of validation for the IRCSEE system at $100 \%$ reading rate

Table 2 Testing Results at $100 \%$ Reading Rate

\begin{tabular}{|c|c|c|c|}
\hline Trials & $\begin{array}{c}\text { Total No. of system } \\
\text { recommendations }\end{array}$ & $\begin{array}{c}\text { No. of system } \\
\text { recommendations } \\
\text { included in the } \\
\text { sample pairs }\end{array}$ & $\begin{array}{c}\text { Recom } \\
\text { Acc } \\
(\%)\end{array}$ \\
\hline 1 & 45 & 43 & 95.56 \\
\hline 2 & 45 & 43 & 95.56 \\
\hline 3 & 48 & 46 & 95.83 \\
\hline 4 & 48 & 45 & 93.75 \\
\hline 5 & 48 & 46 & 95.83 \\
\hline 6 & 42 & 40 & 95.24 \\
\hline 7 & 42 & 40 & 95.24 \\
\hline 8 & 45 & 43 & 95.56 \\
\hline 9 & 48 & 46 & 95.83 \\
\hline 10 & 45 & 43 & 95.56 \\
\hline
\end{tabular}

Table 2 presents the testing result of this scenario in 10 repeated trials. It can be seen from the table that the RecomAcc of the ten trials remains stable and achieves an overall average accuracy 
of about $95.39 \%$, indicating a high level accuracy of the IRCSEE system in providing apparel collocation recommendations, which satisfy the practical requirements of apparel retailers.

Similarly, the RecomAcc at other reading rates are tested, and Fig. 21 shows the average accuracy of the ten trials at each reading rate. It can be seen from the figure that the IRCSEE system performs better in providing apparel collocation recommendations with higher reading rates. Recommendation accuracy higher than $90 \%$, which is practically satisfactory for apparel retailers, is achieved at reading rate of $95 \%$ and $100 \%$, indicating the proposed IRCSEE system is capable to provide satisfactory collocation recommendations in the apparel retail store with appropriate settings of RFID hardware devices. In other words, the IRCSEE system can successfully recommend apparel collocation pairs considering both fashion expertise and customer preferences.

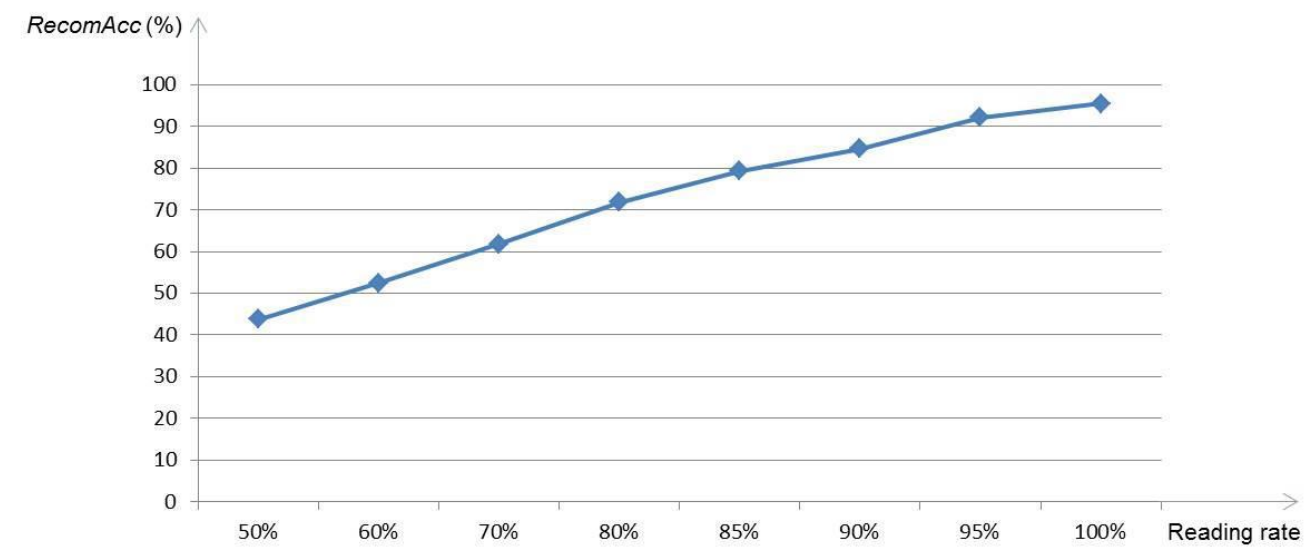

Fig.21. Average recommendation accuracy of the IRCSEE system at different reading rate

In the IRCSEE system, the recommendation degree of each collocation pair keeps changing as the degree of product category popularity is dynamic determined by real-time CSB data. When a customer inputs his/her requirements for gender, occasion and age via the user interface of the RFID-enabled sales-floor kiosk, all the collocation results satisfy these requirements can be searched out from the database and ranked in a descending order of recommendation degree. The top three results are then selected to display on the interface as recommendations for customers. As such, personalized apparel collocation recommendations integrating both fashion expertise and customer preferences are provided to enhance CSE and thus increase sales volume of the retailer.

\section{Conclusion and Future Work}

In this paper, an item-level RFID-enabled system is presented for enhancement of CSE in apparel retail business. RFID hardware devices are implemented in the retail store for CSB collection. An innovative algorithm is designed for accurate recognition of the real-time CSB from RFID raw data. Furthermore, a fuzzy screening algorithm is adopted in the SACR application to automatically generate apparel collocation recommendations based on the customer preferences, the design features of products, and the sales history accumulated in the database collected by RFID hardware devices. The validation tests demonstrated that the proposed system is effective in 
recommending suitable collocation pairs among a class of apparel items. This system is designed for intra-organizational supply chains, especially for relatively high-end apparel retail stores. It exhibits the following characteristics and advantages.

1) In comparison with the existing systems which analyse static or historical data, the proposed system has high reliability because practical data are collected for analysis and applications in real time;

2) Implementation and maintenance of the proposed system is relatively easy, because it is owed and managed by product brand owners or trusted third parties who can mandate compliant rules to all involved partners;

3) Compared with the value of relatively high-end products, the cost of the proposed system is justifiable;

4) The architecture of the proposed system is scalable and can be conveniently adapted for other products. The system focuses on real-time data collection and analysing approaches rather than some specific types of products.

The contributions of this research can be summarised as follow.

1) Formulating an appropriate data format for PID of apparel items. This research identifies the numbering scheme of PID format for programming the C1G2 UHF RFID tags attached to individual apparel product items during manufacturing in an intra-organizational supply chain. Detailed information of production and product properties are stored accordingly to facilitate subsequent inventory and collocation recommendation application.

2) Incorporating RFID hardware devices in the apparel retail environment to collect real-time CSB data. This method not only enhances shopping as a leisure activity by freeing customers from stuffed merchandise, but also helps infer customer preferences for business decisionmaking and proactive individual marketing. Additionally, an innovative BCR algorithm has been developed based on the reading density of RFID tags and the K-means clustering to accurately collect Browsed CSB.

3) Using the FS algorithm to automatically generate recommendations for apparel collocation by considering both the static knowledge of fashion expertise and the dynamic customer preferences to better fit the versatility of the apparel and fashion industry.

4) Developing laboratorial experiments to validate the proposed IRCSEE system, as well as to facilitate practical implementation of RFID in retail stores.

The proposed approaches and algorithms in this research are also applicable to other similar industries, such as high-end cosmetics and wines, because of the following reasons.

1) The numbering scheme for PID is tailor-made and can be adjusted to uniquely identify products in other industries;

2) General behaviour including browsing, carting and purchasing of a shopping process in the apparel retail store are similar to other types of products. As such, the concepts of CSB and the corresponding recognition algorithms can be applied accordingly; 
3) The critical implementation issues of item-level RFID in the real-life environment are quite similar for different industries. For instance, improvement of RFID reading rate and processing of RFID raw data are commonly involved in various RFID-based applications. In this regard, the proposed approaches and algorithms are not restricted to apparel products but can be applied in other industries.

Nevertheless, the proposed system suffers some limitations. First, the FS algorithm only considers three major kinds of apparel properties and two apparel items for collocation. It can be further extended with more properties and apparel items to provide better collocation recommendations. Second, the proposed system can be further developed to facilitate omni-channel retailing by integrating with intelligent mobile devices and social network services to enrich customers with a more convenient interaction and sharing of the collocation recommendations. Moreover, the system is restricted to intra-organizational supply chains. It would therefore be worthwhile to be extended to inter-organizational applications by incorporating modelling techniques like multiagent and multi-tier networking to handle issues of information asymmetry, decentralized and distributed decision-making.

\section{References}

[1] M. Bikshorn, "From customer service to customer experience enhancement," Customer Experience Reporting. Retrieved March 8, 2011, from http://www.serviceexcellencegroup.com.

[2] T. Kent, "Creative space: design and the retail environment," International Journal of Retail and Distribution Management, vol. 35, pp. 734-745, July 2007.

[3] J.B. Kim, Y. Koo, and D. R. Chang, "Integrated brand experience through sensory branding and IMC,” Design Management Review, vol. 20, pp. 72-81, September 2009.

[4] J.L. Hou and T.G. Chen, "An RFID-based shopping service system for retailers," Advanced Engineering Informatics, vol. 25, pp. 103-115, January 2011.

[5] P.J. Trocchia and M.G. Luckett, "Transitory bias as a source of customer dissatisfaction: an exploratory investigation,” Journal of Consumer Behaviour, vol. 12, pp. 32-41, January 2013.

[6] J.Z. Raja, D. Bourne, K. Goffin, M. Çakkol, and V. Martinez, " Achieving customer satisfaction through integrated products and services: an exploratory study," Journal of Product Innovation Management, vol. 30, pp. 1128-1144, November 2013.

[7] Z.X. Guo, W.K. Wong, S.Y.S. Leung and M. Li, "Applications of artificial intelligence in the apparel industry: a review," Textile Research Journal, vol. 81, pp. 1871-1892, June 2011.

[8] J. McCarthy, M.L. Minsky, N. Rochester and C.E. Shannon, ""A proposal for the Dartmouth summer research project on artificial intelligence," Retrieved August 30, 2007, from http://www-formal.stanford.edu/jmc/history/dartmouth/dartmouth.html.

[9] M. Ko, A. Tiwari and J. Mehnen, "A review of soft computing applications in supply chain management,” Applied Soft Computing, vol. 10, pp. 661-674, June 2010.

[10] Y. Yu, Y, T.M. Choi and C.L. Hui, "An intelligent fast sales forecasting model for fashion products,” Expert Systems with Applications, vol. 38, pp. 7373-7379, June 2011.

[11]F.L. Chen, T.Y. Ou, "Sales forecasting system based on Gray extreme learning machine with Taguchi method in retail industry," Expert System with Application, vol. 38, pp. 1336-1345, March 2011. 
[12] W.K. Wong , X.H. Zeng and W.M.R. Au, "A decision support tool for apparel coordination through integrating the knowledge-ba sed attribute evaluation expert system and the T-S fuzzy neural network," Expert System with Application, vol. 36, pp. 2377-2390, March 2009.

[13]X.J. Wang, H.K. Chan, R.W.Y. Yee and I.Diaz-Raineya, "A two-stage fuzzy-AHP model for risk assessment of implementing green initiatives in the fashion supply chain," International Journal of Production Economics, vol. 135, pp. 595-606, February 2012.

[14]C.L. Hui, T.W. Lau S.F. Ng and C.C. Chan, "Learning-based fuzzy colour prediction system for more effective apparel design," International Journal of Clothing Science and Technology, vol. 17, pp. 335-348, 2005.

[15] W.K. Wong, X.H. Zeng, W.M.R. Au, P.Y. Mok, and S.Y.S. Leung, "A fashion mix-andmatch expert system for fashion retailers using fuzzy screening approach," Expert Systems with Applications, vol. 36, pp. 1750-1764, March 2009.

[16]C.I. Cheng and D.S.-M. Liu, "An intelligent clothes search system based on fashion styles," in 2008 Int. Conf. Machine Learning and Cybernetics, Kunming, China, 2008, pp. 15921597.

[17]X. Li, H.X. Yao, X.S. Sun, R.R. Ji, X.M. Liu and P.F. Xu, "Sparse representation based visual element analysis," in $18^{\text {th }}$ IEEE Int. Conf. Image Processing, Brussels, 2011, pp.657660.

[18]A.H. Dong, D. Shan, Z. Ruan, L.Y. Zhou and F. Zuo, "The design and implementationof an intelligent apparel recommend expert system," Mathematical Problemsin Engineering, vol. 2013, Article ID 343171, 8 pages, 2013. doi:10.1155/2013/343171

[19]A. Sarac, N. Absi and S. Dauzere-Peres, "A literature review on the impact of RFID technologies on supply chain management," International Journal of Production Economics, vol. 128, pp. 77-95, November 2010.

[20]I.P. Vlachos, "A hierarchical model of the impact of RFID practices on retail supply chain performance," Expert Systems with Applications, vol.41, pp. 5-15, January 2014.

[21]Y. Rekik, E. Sahin, and Y. Dallery, "Analysis of the impact of the RFID technology on reducing product misplacement errors at retail stores," International Journal of Production Economics, vol. 112, pp. 264-278, March 2008.

[22]K. Reinhardt, "RFID item-level tagging in fashion apparel \& footwear: one-size-fits-all solution for retail business process improvement," ABI Research, Oyster Bay, NY, September 2009.

[23] A.D. Macro, A.C. Cagliano, M.L. Nervo, and C. Rafele, "Using system dynamics to access the impact of RFID technology on retail operations," Internal Journal of Production Economics, vol. 135, pp. 333-344, January 2012.

[24]C. Metzger, F. Thiesse, S. Gershwin, and E. Fleisch, "The impact of false-negative reads on the performance of RFID-based shelf inventory control policies," Computers and Operations Research, vol. 40, pp. 1864-1873, July 2013.

[25]H.H. Cheung and S.H. Choi, "Implementation issues in RFID-enabled anti-counterfeiting systems," Computers In Industry, vol. 62, pp. 708-718, July 2011.

[26]EPCTM radio-frequency identity protocols class-1 generation-2 RFID protocol for communications at $860 \mathrm{MHz}-960 \mathrm{MHz}$ v1.7, EPCglobal Inc., 2013.

[27]X.S. Zhang and D. Wang, "Entity information retrieval system based on EPC network," in J. J. J. H. Park (Ed.), Multimedia and Ubiquitous Engineering, Berlin, German: SpringerVerlag, 2014. 
[28]N. Adhiarna, Y.M. Hwang, and J.J. Rho, "A two-dimensional framework for RFID adoption and diffusion: strategic implications for developing countries," Journal of Technology Management \& Innovation, vol. 6, pp. 176-188, June 2011.

[29] S. Evdokimov, B. Fabian, and O. Gunther, RFID and the Internet of Things: Technology, Applications, and Security Challenges. Delft, Netherlands: Now Publishers, 2011.

[30]Monza 4 Tag Chip Datasheet, Impinj, January 20, 2015.

[31]W.G. Wu, Fashion Aesthetics, 4th ed., Beijing, China: China Textile \& Apparel Press, 2013.

[32]C. Decker, U. Kubach, and M. Beigl, "Revealing the retail black box by interaction sensing," in Proc. 23rd Int. Conf. Distributed Computing Systems, Providence, RI, 2003, pp. 328-333.

[33]F.R. Kardes, M.L. Cronley, and T.W. Cline, Consumer Behavior. Mason, OH: SouthWestern Cengage Learning, 2011.

[34]W. Karwowski, M.M. Soares, and N.A. Stanton, Human Factors and Ergonomics in Consumer Product Design: Uses and Applications. Boca Raton, FL: CRC Press, 2011.

[35]C. Schmid, "Course on dynamics of multidisplicinary and controlled systems," Retrieved May 2005, from http://www.atp.ruhr-uni-bochum.de/rt1/syscontrol/main.html.

[36]A. Aksoy, N. Ozturk and E. Sucky, "A decision support system for demand forecasting in the clothing industry," International Journal of Clothing Science and Technology, vol. 24, pp. 221 - 236, July 2012.

[37]L. E. Sigler, Fibonacci's Liber Abaci: A Translation into Modern English of Leonardo Pisano's Book of Calculation. New York: Springer-Verlag, 2002.

[38]C. Carlsson and R. Fuller, "On fuzzy screening system," In: Proceedings of European Congr. on Intelligent Techniques and Soft Computing, Aachen, Germany, 1995.

[39] Y. Shi, "A deep study of fuzzy implications," Ph. D. dissertation, Dept. Applied Mathematics and Computer Science, Ghent Univ., Ghent, Belgium, 2009. 